EGU21-14129, updated on 16 Nov 2021

https://doi.org/10.5194/egusphere-egu21-14129

EGU General Assembly 2021

(c) Author(s) 2021. This work is distributed under

the Creative Commons Attribution 4.0 License.

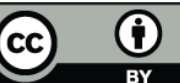

\title{
The deep underground Callio SpaceLab, Finland - Sustainable living, sustaining life
}

\author{
Jari Joutsenvaara ${ }^{1,2,3}$, Marko Aittola ${ }^{2,3,4}$, Marko Holma ${ }^{1,2,3}$, Ossi Kotavaara ${ }^{1}$, Eija-Riitta Niinikoski ${ }^{1}$, \\ Sakari Nokela ${ }^{5}$, and Teemu Öhman ${ }^{2}$ \\ ${ }^{1}$ University of Oulu, Kerttu Saalasti Institute, Nivala, Finland (jari.joutsenvaara@oulu.fi) \\ ${ }^{2}$ Arctic Planetary Science Institute, Äänekoski, Finland \\ ${ }^{3}$ Muon Solutions Oy, Saarenkylä, Finland \\ ${ }^{4}$ University of Jyväskylä, Kokkoka University Consortium Chydenius, Finland \\ ${ }^{5}$ Quantum Properties Ltd, Pyhäjärvi, Finland
}

Callio Lab, the host of Callio SpaceLab, is a unique underground infrastructure located at the depths of the Pyhäsalmi mine, Finland. It is one of the cornerstones of the 'Callio - Mine for business' concept. The Callio concept aims to create and maintain an economically feasible environment for all mine re-purposing activities at the mine site. [1,2].

The Pyhäsalmi mine is one of the deepest base metal mines in Europe with a depth of $1.4 \mathrm{~km}$. The underground mining operations are ending in 10/2021. While the mine is closing, new doors open for various underground re-use activities with access 24/7 to underground facilities. With minewide optical network access, the re-use activities can be remotely monitored securely online. The mine infrastructure, including its underground facilities, offers a unique testing and analogue simulation environment, for example, for the future Lunar and planetary missions. Such a habitat environment can be used, for example, to develop and test instrumentation (e.g., detectors, drills, tools, and rovers), construction, maintenance, and food, energy and mineral resource production technologies, as well as to study solutions and psychological impacts related to architecture, underground lighting, crew interaction, and team performance. The multidisciplinary University of Oulu, Finland, supports the scientific work at the site. The scientific activities are coordinated by the Kerttu Saalasti Institute of the same university [3]. Currently, six underground laboratories are operational, including cosmic ray monitoring, underground food production (insect -farming, hydroponic greenhouses), underground safety and rescue training, intelligent and biodynamic underground lighting, and isotope analysis facility.

The Pyhäsalmi Mine is situated in a volcanogenic massive sulphide (VMS) deposit formed ca. 1.9 $\mathrm{Ga}$ and offers excellent possibilities for testing and simulating resource extraction for future Lunar and planetary missions in a safe and effective manner. Due to the origins of the ore deposit, most wall rocks along the tunnels represent submarine mafic volcanic rocks. Moreover, the rocks contain some ancient saline water pockets. The water samples analysis has shown traces of Firmicute, Beta- and Gammaproteobacteria species common in deep subsurface environments. 
The water pockets are sealed and equipped with valves for future analyses. [4].

In our talk, the possibilities and development plans of the Callio SpaceLab are discussed in further detail.

[1] Callio Lab - Underground Center for Science and R \& D, www.calliolab.com, 8 Jan 2021

[2] Mine for Business - Callio - Pyhäjärvi, Finland, www.callio.info, 8 Jan 2021

[3] Kerttu Saalasti Institute, www.oulu.fi/ksi-eng, 8 Jan 2021

[4] Miettinen H., Kietäväinen R., Sohlberg E., Numminen M., Ahonen L. \& Itävaara M.. Microbiome composition and geochemical characteristics of deep subsurface high-pressure environment, Pyhäsalmi mine Finland, Frontiers in Microbiology, p. 1203, Vol 6, 2015. 